\title{
Reflections on the Combination of Computer Assisted Technology and Higher Vocational Education
}

\author{
Zhaohui Yang \\ Harbin Vocational \& Technical College, Harbin, Heilongjiang, 150081
}

Keywords: Computer Aided Technology; Higher Vocational Education Integration; Effective Measures

\begin{abstract}
With the continuous development of science and technology in our country, computer technology has been widely used in all fields of social production. As an important place for delivering a large number of high-quality talents to the society, the vocational education school occupies an important position in the education system. At this stage, most of the higher vocational teachers are influenced by the traditional teaching concept. In the process of classroom teaching, the traditional teaching method is still adopted, which severely weakened students' enthusiasm for learning. However, introducing computer-aided technology into higher vocational teaching can be used in active classroom teaching Atmosphere at the same time fully stimulate the enthusiasm of students to effectively improve the quality of classroom teaching. Based on the actual situation, this article analyzes the integration of computer-aided technology and higher vocational education in order to effectively improve the teaching level of higher vocational education.
\end{abstract}

\section{Introduction}

In the course of the development of the times, the traditional teaching methods have been unable to adapt to the current teaching needs, which requires higher vocational teachers in the teaching process in the future, actively participate in the school to carry out the teaching reform, and strictly follow the new curriculum standards in the requirements of the people-oriented as The main principles of classroom teaching, advancing with the times, fully grasp the computer technology, in the classroom teaching process into the computer-aided technology, make full use of the characteristics of computer technology diagram, text and sound, to mobilize the enthusiasm of students to stimulate students interest in learning for Students to create a good classroom teaching atmosphere, on the basis of which clear their own guidance in the teaching process to give students the correct guidance to improve student learning quality and efficiency. Based on the actual situation, this article analyzes the integration of computer aided technology and higher vocational education, and provides valuable experience for future education.

\section{The necessity of computer aided technology and vocational education integration analysis}

Affected by the traditional teaching concept, most of the current vocational teachers in the classroom teaching process is mainly using cramming, full of irrigation teaching methods, to instill knowledge of students, and students in the actual teaching process can only be taught by teachers related knowledge Memory, can not autonomously think about these knowledge, leading students to form solidified thinking in the long-term learning process, lack of self-learning ability is not conducive to student learning and development in the future, and computer-aided technology into higher vocational teaching, you can improve the traditional teaching The shortcomings of the way, at the same time can stimulate students interest in learning, is a more effective classroom teaching methods [1]. First of all, the use of computer-assisted technology for classroom teaching can enrich the content of classroom teaching. Because higher vocational education includes specialized courses, classroom teaching of professional courses usually has a certain degree of abstraction, which causes certain difficulties for students' professional study. For example, when teaching a course of "cold stamping design", a teacher needs to design a plurality of teaching links such as principle teaching, 
machine structure understanding and working process presentation. If traditional teaching methods are used, the teacher can only teach students Teaching related knowledge is affected by the objective environmental factors. Teachers can not move the objects into the classroom for teaching, thus hindering the classroom teaching. However, integrating computer-aided techniques into classroom teaching can effectively improve the situation and break the time, Space constraints, the use of computers to teach students about the "cold stamping" related knowledge, at the same time the use of micro-class to show students the "cold stamping" process, to deepen the students understanding of this part of the content of knowledge in order to improve the quality of classroom teaching.

Secondly, through the use of computer-aided technology, the scattered information in the network can be integrated to provide effective teaching resources for students. The teaching platform can be used to transfer high-quality learning resources to students and guide students to adopt interactive learning methods to fully stimulate students' interest in learning. Mobilize the enthusiasm of students to create a good learning atmosphere for students [2]. In the traditional teaching methods, the use of flip chart, sound recording, video recording and other ways can enhance students' interest in learning to a certain extent, and can achieve certain teaching effect. However, due to these teaching information is too fragmented to achieve the best teaching effect. If in the classroom teaching process of computer-aided integration of organic integration in teaching, you can integrate the information resources in the network, will help the classroom teaching, and classroom teaching content consistent with the teaching content filtering, filtering, so that students can teach in the classroom In the process, we should concentrate our attention, stimulate students' interest in learning, encourage students to think independently about relevant knowledge so as to improve students' ability of thinking, exploring ability and autonomous learning, and lay a good foundation for students' future study and development.

\section{The current computer-aided teaching problems}

First of all, in the actual teaching process, the higher vocational teachers exist the classroom teaching in the form of "observing class", just as a small part of the content in the classroom teaching. The main reason for this phenomenon is that the computer aided technology is not fully integrated with the classroom teaching Is because teachers want to apply computer-aided technology to classroom teaching organically, which requires a great deal of time and effort to develop courseware independently. However, teachers are more busy and do not have enough time to prepare for classroom teaching [3]. Secondly, there are a large number of teaching softwares in the network environment at present, however, there are only a few teaching softwares that are really suitable for them. Therefore, most of the teachers need to make their own courseware compilation in the course of using CAD technology for classroom teaching. However, In the widespread teacher written manuscripts, computer technicians to complete the programming work, the development of small teaching software. Under normal circumstances, vocational teachers do not have a high computer technology, and the operation is limited, which makes the role of teaching software can not be effectively played in classroom teaching, seriously affecting the quality of classroom teaching. Second, teachers in the actual teaching process, focusing only on teacher dominance. Under normal circumstances, the use of computer-assisted technology for teaching, the need to combine the actual situation of teaching in the classroom to carry out related teaching work, at the same time with the teaching content courseware design. However, most teachers ignore this point in the actual teaching process, neglect the students 'subjectivity and focus only on teaching. They fail to fully consider whether students can accept relevant teaching contents or not, which is unfavorable to students' future learning and development. Finally, in the process of classroom teaching, most of the higher vocational teachers simply use the computer to teach students relevant theoretical knowledge, lack of communication and exchange with students, resulting in the lack of practice in the classroom teaching process, students can not fully understand and master the professional Knowledge, and student thinking ability can not be effectively expanded. Although this teaching method integrates computer-assisted instruction into classroom teaching, it restricts the 
direction of teachers' classroom teaching. It only takes the content of teaching software as its theme to carry out relevant teaching work, which runs counter to the nature of computer-assisted instruction [4].

\section{To solve the problem of computer-aided teaching effective measures}

Interest is the best teacher, only fully stimulate students interest in learning, can promote students to participate in the future autonomy in teacher-organized classroom teaching activities. With the continuous deepening of the new curriculum reform, the teaching objectives of higher vocational education gradually change, requiring teachers in the classroom teaching process to cultivate students 'thinking ability, practice exploration ability, independent learning ability as the main goal, while respecting students' subjective position. Therefore, the higher vocational teachers in the future classroom teaching should stimulate students interest in learning, and fully mobilize the enthusiasm of students as the primary task to promote students' full play to the subjective initiative to expand student thinking. By applying computer-aided technology to classroom teaching, students' interest in learning can be stimulated on the basis of enriching classroom teaching content so that students can fully grasp relevant theoretical knowledge under the guidance of teachers and play video in courseware to further understand the teaching material Teaching theoretical knowledge, and actively explore and practice under the class, effectively improve students' ability to learn independently, explore the ability and practical ability, and lay a good foundation for the students to learn and develop in the future [5].

Although the new curriculum standards require that higher vocational teachers follow the "people-oriented" principle in the actual teaching process and clarify the dominant position of students in the process of classroom teaching, teachers still play an important role as the organizer and director of classroom teaching [6]. Therefore, the higher vocational teachers in the future classroom teaching, should make relevant teaching design in advance, combined with the relevant content of the new curriculum standards, rational design of teaching content in order to ensure the effectiveness of classroom teaching, teachers should pay attention to communication with students, Only in this way can we grasp the students 'learning situation and psychological status in time, carry out relevant teaching work according to the actual situation of the students, create a good classroom teaching atmosphere for the students, give full play to their own guiding role on the basis of respecting the students' main body status, Grasp the relevant knowledge, through the correct way to pass on to students, to help students understand the theoretical knowledge. For example, teachers in the "injection molding machine working principle" part of the content, you can add animation in the courseware, at the same time the use of animation, multimedia playback and other ways to show the working principle to students, while completing the theoretical knowledge of teaching, but also allow students Fully understand the operating status of the injection molding machine to further enhance the students understanding of the working principle of the injection molding machine, after the end of the lecture, teachers can organize students to discuss the group within the group on the working principle of injection molding machines and related theoretical knowledge to deepen to deepen Students understand the content of classroom teaching. At this time, teachers should enter the group. If the students have the problem of comprehension, the students should be given the right guidance at the first time in order to prevent the students from understanding the deviation and affect the future study.

Computer-aided technology requires a large number of courseware that can be effectively applied in the teaching process. However, due to the large amount of courseware produced, most teachers can not rely solely on their own ability to complete the software production, and need to consume a lot of time and effort [7]. In order to effectively solve this problem, vocational colleges should set up computer-aided teaching courseware development and research center in the school to form a rich teaching experience and the composition of the art design, programming, educational technology, psychology and music workers Software research and development team, tailor-made for the various teaching courseware, to better serve the teaching and research.

Since most teachers do not have high computer skills, they can not make full use of 
computer-aided techniques to complete relevant teaching work in the course of classroom teaching. Therefore, in the future work of the school should pay attention to the teacher computer technology training to enhance the level of computer teachers. Through the establishment of a sound computer aided training system in schools, teachers are encouraged to actively participate in various forms of computer training. Under the new era, higher vocational teachers should keep pace with the times and actively participate in all kinds of computer technology training centers organized by the schools so as to further improve the level of computer aided instruction. At the same time, a perfect incentive mechanism and training learning assessment should be established System, regularly or irregularly on the computer level of vocational teachers to conduct spot checks, and urge teachers to complete the relevant training content in order to improve the level of computer technology teachers, lay a solid foundation for future classroom teaching [8].

First of all, to achieve the teaching objectives on the Internet, arrange teaching content, implement teaching strategies, carry out teaching activities and provide online teaching support environment and other issues. First of all, we should change the influence of traditional school education concept and face-to-face mode, carry out the student-centered and teacher-led spirit, study and exert the characteristics and advantages of online teaching, truly integrate information technology with curriculum, and not use information technology as a supplementary teaching Secondly, pay attention to the instructional design of online courses, fully embody the dominant position of students, make rational use of multimedia and other means to make information technology into the curriculum and prevent the texts and face-to-face teaching materials from simply being put on the Internet. In this way, students can break the limitation of time and space, carry out related learning independently according to their own needs, and make learning plans reasonably according to their own mastery of professional knowledge so as to effectively improve the quality and efficiency of students' learning.

\section{Conclusion}

In summary, with the continuous deepening of the new curriculum reform, the traditional teaching methods can no longer meet the current classroom teaching needs, and the development of science and technology has also prompted computer-aided technology to become part of classroom teaching an important part. Therefore, in the process of teaching in the future, teachers in higher vocational colleges should fully recognize the important role of computer-aided technology in improving the quality of classroom teaching in higher vocational colleges, clarify the dominant position of students in the classroom as well as their own guiding role, integrate teaching with computer-aided techniques, Teaching atmosphere at the same time fully stimulate student interest in learning, so that students in the future learning process to actively participate in classroom activities organized by teachers, and the formation of independent study habits for the students to lay a good foundation for future learning and development.

\section{Acknowledgements}

Heilongjiang Province Education Science Planning "Twelfth Five-Year" key project "backbone of vocational colleges and innovative entrepreneurship education mode" subject number ZJB1215006.

Heilongjiang Provincial Institute of Higher Education "Thirteen Five" research project of higher education "Higher Vocational Education modern apprentice system training mode" subject number $16 Z 089$.

\section{References}

[1] Cheng Baojuan. The Application of New Computer Technology in Higher Vocational Education [J]. Art Liberal Navigation (Middle), 2014 (6): 87-87.

[2] Gu Pengyao. Study on the Application Strategy of "Micro-class" in Higher Vocational Education 
* - Taking the Course of "Basic Computer Network" as an Example [J]. Computer times, 2015 (9): 56-58.

[3] LIU Hai-rong. Application of Computer Virtual Laboratory in Higher Vocational Education [J]. West Leather, 2016,38 (2): 237.

[4] Chen Yan. Modularization in the computer multimedia professional teaching of higher vocational education [J] Talent, 2016 (27): 45.

[5] Hou Jianqun. On the reform of "basic computer application" in higher vocational education [J]. Journal of Youth and Society, 2013 (28): 160-160,161.

[6] Huang Weihua. Exploration of Teaching Methods of Computer Science Courses in Higher Vocational Education [J]. Journal of Information and Computer, 2017 (14): 222-223.

[7] Wang Yan. Application of "Flipped Classroom" in Higher Vocational Education - A Case Study of Computer Information Technology [J]. New China New Telecommunications, 2016,18 (6): 35-35.

[8] Pan Hongtao. Development and Application of Computer Network Simulation Model Library in Higher Vocational Education [J]. Electric Power Education in China, 2014 (33): 95-96,105. 